\title{
O PAPEL DA AFETIVIDADE NA RELAÇÃO PROFESSOR E ALUNO E SUA IMPLICAÇÕES NA APRENDIZAGEM
}

\author{
EL PAPEL DE LA AFECTIVIDAD EN LA RELACIÓN PROFESOR Y ALUMNO Y \\ SUS IMPLICACIONES EN EL APRENDIZAJE
}

\author{
THE ROLE OF AFFECTIVITY IN THE RELATIONSHIP BETWEEN TEACHER \\ AND STUDENT AND ITS IMPLICATIONS IN LEARNING
}

Maria Fabrícia de MEDEIROS ${ }^{1}$

RESUMO: O presente trabalho teve como objetivo geral verificar se as relações entre professor e aluno no cotidiano da sala de aula influenciam no processo de ensino e aprendizagem. Procuramos elencar, reflexões teóricas e metodológicas sobre as ações e meios utilizados pelas escolas no trabalho com a temática afetividade, ensino e aprendizagem e a postura do professor no que diz respeito à valorização da afetividade em sua prática e vivência em sala de aula. O referencial teórico foi pautado nos estudos e reflexões de autores que trazem reflexões sobre a questão afetiva, sendo esta primordial na construção das relações humanas, bem como discussões das relações que acontecem dentro do ambiente escolar e influenciam a construção da identidade, autonomia e aprendizagem dos alunos. Entretanto, trabalhar efetivamente com uma temática tão profunda, possibilitou perceber que a afetividade está diretamente ligada ao ensino e a aprendizagem. Apesar das dificuldades encontradas no que diz respeito a convivência entre os indivíduos e suas diferenças, é possível desenvolver uma educação escolar pautada em ações afetivas eficazes, promovendo a autonomia e o desenvolvimento global dos alunos. Atualmente, faz-se necessário aprofundar e trabalhar a questão afetiva, uma vez que os valores primordiais têm sido deixados de lado nas relações humanas. A partir dessa premissa, para consecução efetiva deste trabalho, foi realizada uma pesquisa bibliográfica em que foram utilizadas fontes como: livros, periódicos, resumos, artigos, monografias, dissertações e teses.

PALAVRAS-CHAVE: Ensino e aprendizagem. Afetividade. Relação professor e aluno.

RESUMEN: El presente trabajo tuvo como objetivo general verificar si las relaciones entre profesor y alumno en el cotidiano del aula influencian en el proceso de enseñanza y aprendizaje. En el trabajo con la temática afectiva, la enseñanza y el aprendizaje y la postura del profesor en lo que se refiere a la valorización de la afectividad en su práctica y vivencia en el aula, buscamos elencar, reflexiones teóricas y metodológicas sobre las acciones y medios utilizados por las escuelas en el trabajo con la temática afectiva, enseñanza y aprendizaje. El referencial teórico fue pautado en los estudios y reflexiones de autores que traen reflexiones sobre la cuestión afectiva, siendo esta primordial en la construcción de las relaciones humanas, así como discusiones de las

${ }^{1}$ Universidade Federal da Paraíba (UFPB), João Pessoa - PB - Brasil. Doutoranda pelo Programa de PósGraduação em Educação-PPGE. Professora Efetiva Municipal. E-mail: fabriciamedeiros@ hotmail.com 
relaciones que ocurren dentro del ambiente escolar e influencian la construcción de la identidad, autonomía y aprendizaje Los alumnos. Sin embargo, trabajar efectivamente con una temática tan profunda, posibilitó percibir que la afectividad está directamente ligada a la enseñanza y el aprendizaje. A pesar de las dificultades encontradas en lo que se refiere a la convivencia entre los individuos y sus diferencias, es posible desarrollar una educación escolar pautada en acciones afectivas eficaces, promoviendo la autonomía y el desarrollo global de los alumnos. Actualmente, se hace necesario profundizar y trabajar la cuestión afectiva, ya que los valores primordiales se han dejado de lado en las relaciones humanas. A partir de esta premisa, para la consecución efectiva de este trabajo, se realizó una investigación bibliográfica en la que se utilizaron fuentes como: libros, periódicos, resúmenes, artículos, monografías, disertaciones y tesis.

PALABRAS CLAVE: Enseñanza y aprendizaje, afectividad, relación profesor y alumno.

ABSTRACT: The present work had as general objective to verify if the relations between teacher and student in the daily life of the classroom influence in the process of teaching and learning. We seek to elencar, theoretical and methodological reflections on the actions and means used by schools in the work with the theme of affectivity, teaching and learning and the teacher's attitude regarding the valuation of affectivity in their practice and experience in the classroom. The theoretical framework was based on the studies and reflections of authors who bring reflections about the affective question, being this primordial in the construction of human relations, as well as discussions of the relationships that take place within the school environment and influence the construction of the identity, autonomy and learning of the Students. However, working effectively with such a deep theme enabled us to perceive that affectivity is directly linked to teaching and learning. Despite the difficulties encountered regarding the coexistence between individuals and their differences, it is possible to develop a school education based on effective affective actions, promoting autonomy and the overall development of students. Today, it is necessary to deepen and work on the affective question, since the primordial values have been left aside in human relations. Based on this premise, a bibliographical research was carried out in which sources such as: books, periodicals, abstracts, articles, monographs, dissertations and theses were used.

KEYWORDS: Teaching and learning. Affectivity. Teacher and student relationship.

\section{Introdução}

A afetividade nas relações estabelecidas no contexto escolar entre professor e aluno são temas discutidos e analisados há muitos anos por vários estudiosos que acreditavam ter nesse sentimento a chave para uma educação eficaz e duradoura, capaz de transformar os indivíduos e torná-los, consequentemente, cidadãos preparados para conviver com as adversidades do mundo. Tendo em vista que as dificuldades afetivas são fortes desestabilizadores comportamentais, que, se mal acompanhadas, podem 
perpetuar-se por toda a vida pessoal e escolar, faz-se necessária uma conscientização, bem como mudanças de atitudes, principalmente no que diz respeito às relações afetivas dentro da escola que é nosso foco de estudo neste texto, em busca de tentar reverter à realidade preocupante que encontramos dentro das escolas atualmente como assinalam Tognetta e Vinha (1999) lembrando que ao discutirem com professores deparam-se com um saudosismo no que concerne aos valores outrora comuns à outras gerações que sofreram mudanças atualmente e que se questionam se os valores atuais são morais.

A família é, indiscutivelmente, a principal responsável pelos primeiros ensinamentos e cuidados com as crianças e jovens. Consciente ou inconscientemente, ela prepara os filhos para conviver em sociedade, imprimindo pensamentos e ações de acordo com sua cultura; posteriormente, surge a escola, com o objetivo de ensinar conteúdos, mas também imprimindo regras e normas de convivência muito explícitas, sendo que os alunos são cobrados por cumpri-las nas relações que estabelecem dentro deste ambiente tão heterogêneo.

Trabalhar com a perspectiva afetiva é fazer aflorar sentimento de tolerância, de respeito a si e ao próximo. Na sociedade atual, marcada pelo sistema capitalista, onde a busca do ter é mais importante que a do ser, os sentimentos de humanização ficaram relegados, quando muito, à segundo plano, e, certamente, não estão cumprindo sua esperada e essencial função na transformação e relações entre os indivíduos.

Por ser um espaço de socialização de saberes, a escola vem enfrentando o desafio constante de conscientização dos seus alunos frente à um sistema que integra atitudes e ações pautadas na competição e no individualismo. Apesar do cenário, antes apresentado, alguns teóricos têm dedicado tempo para estudos na área da afetividade nas relações entre professor e alunos. Eles discutem ressaltando uma perspectiva de trazer reais mudanças para a educação, mostrando caminhos que apontem o papel da escola, que é o de formar sujeitos críticos, participativos e conscientes de seus direitos e deveres, bem como que consigam interagir socialmente e resolver conflitos.

Portanto, a relevância do tema afetividade é nítida e prerrogativa para que as relações entre professor e aluno sejam construídas e permaneçam embasadas no respeito mútuo, consequentemente refletindo diretamente nos processos de ensino e aprendizagem, porque se sabe que quando o indivíduo é motivado e integrado em suas dimensões afetiva, cognitiva e motora, ele alcança com mais facilidade os objetivos propostos pela escola, que seriam o desenvolvimento parcial ou integral de todas as dimensões acima referidas. É nesse contexto que este trabalho se insere. A escolha do 
tema se deu a partir da observação das inúmeras dificuldades socioafetivas demonstradas pelos alunos em mais de doze anos atuando como professora que vive e presencia diariamente tantos conflitos no ambiente escolar.

Entende-se que um dos meios de acontecer as mudanças educacionais e sociais, tão almejadas principalmente nos dias atuais, que me parecem envoltas por ações tomadas no calor das situações conflitantes, é aquele que tem a afetividade como principal meta à ser seguida constantemente, a qual assumirá uma postura altamente benéfica em relação ao desenvolvimento concreto dos sujeitos envolvidos diretamente na educação, que disseminarão tais comportamentos fora da escola.

Portanto, ao depararmos como professores no cotidiano da sala de aula com situações conflituosas entre os alunos, busca-se com este estudo resposta para um problema que surgiu diante de nossos estudos teóricos: as relações entre professor e aluno no cotidiano da sala de aula influenciam no processo de ensino e aprendizagem?

Para a realização deste trabalho, optou-se por realizar uma Pesquisa Bibliográfica, e foram utilizadas fontes como: livros, periódicos, resumos, artigos, monografias, dissertações e teses.

Diante do exposto, este trabalho tem, como objetivo geral, verificar se as relações entre professor e aluno no cotidiano da sala de aula influenciam no processo de ensino e aprendizagem e, como objetivos específicos, compreender o papel da afetividade no processo de ensino e aprendizagem e analisar se há dificuldade para professores e alunos construírem uma relação saudável e baseada no respeito.

Nessa perspectiva, este estudo possibilitará aos professores refletirem sobre a real função social da escola pautada na consecução de práticas afetivas no cotidiano da sala de aula.

A partir dos estudos bibliográficos e empíricos, constatou-se que somente através da afetividade podem-se obter resultados satisfatórios no que diz respeito ao desenvolvimento, socialização e construção de indivíduos críticos, autônomos e capazes de lidar com as adversidades do cotidiano.

Com a escolha e predileção por esse tema, visamos, em especial, à uma contribuição significativa para a prática pedagógica e para a reflexão de determinados conceitos que permeiam as instituições educacionais, dando-nos oportunidade de construir o melhor caminho e colocando a afetividade em seu lugar de valor e como a base para uma prática diferenciada, que tem como meta uma educação de qualidade. 


\section{A importância da afetividade na relação professor e aluno}

A responsabilidade que o professor tem para a educação é incontestável, pois é ele que ensina, de modo particular, seus alunos para a vida em sociedade. A relação professor e aluno deve ser consistente e baseada na compreensão e confiança mútuas, refletindo-se, consequentemente, na prática pedagógica e na aprendizagem, respectivamente. "Podemos ser bons professores e ao mesmo tempo diferentes; embora haja um perfil claro de bom professor, não se trata de um perfil rígido; os próprios alunos reconhecem que seus bons professores não são todos iguais" (MORALES, 1998, p. 34).

O perfil do que podemos inferir como um bom professor reúne determinadas características indispensáveis ao bom relacionamento com os alunos. Cada professor tem suas particularidades e, embora não haja um perfil que defina este perfil de bom professor, ele deve conscientizar-se de sua responsabilidade diante dos olhos atentos de seus alunos, que fazem escolhas e reconhecem as diferenças entre um professor que desempenha bem o seu trabalho e outro que não apresenta, na sua prática cotidiana, satisfação no desenvolvimento de sua função. Não há um perfil rígido de definição do bom professor; no entanto, há sim as características que o definem como bom, que seriam: motivação, dedicação, compreensão, demonstrar segurança, ser bem preparado não só didaticamente, mas também na resolução de conflitos, entre tantos outros aspectos facilmente detectados pelos alunos, que, em grande parte, passam a espelhar-se em seus professores eleitos bons por eles próprios, e, que os consideram exemplo para si, confirmando-se, assim, a importância de um profissional consciente de sua influência na formação da personalidade dos alunos.

Os objetos principais da educação são os alunos, assim, devem ter seus direitos e necessidades peculiares à cada faixa etária do seu desenvolvimento, respeitados e acompanhados adequadamente para que haja evolução satisfatória do ponto de vista social.

Em distintas idades, as situações e necessidades dos alunos podem ser diferentes; características desejáveis com adolescentes ou préadolescentes (saber manter a ordem, por exemplo) podem ser de importância menor em outras idades, e é importante refletir sobre isso (MORALES, 1998, p. 34).

É correto afirmar que cada indivíduo, dentro de suas especificidades, tem necessidades diferenciadas: podemos citar a mudança de idades como um dos principais 
fatores, já que, a cada fase de desenvolvimento, adquirimos novas características, o que obrigatoriamente nos remete à variados comportamentos e desejos.

No contexto escolar, os alunos apenas reproduzem essas características, demonstrando claramente, na maioria das vezes, suas frustrações, expectativas, entre outros sentimentos que podem ser analisados pelo professor através de traços comportamentais. É essencial que o professor tenha consciência, reflita e aja diante da heterogeneidade que encontrará em seus alunos. Ele deve preparar-se para lidar não apenas com as particularidades de cada faixa etária, mas também com a individualidade dos alunos, entretanto, um ambiente escolar propício ao diálogo e baseado na confiança e respeito deve ser construído pelo professor atento e comprometido com os ideais da profissão, visando ao desempenho próprio e de seus alunos.

A relação professor-aluno deve ser construída primeiramente com base no diálogo. É através deste que podem ser detectadas opiniões e problemas comuns a praticamente todo ser humano e estabelecido o companheirismo entre ambos, traduzindo-se, assim, numa melhor prática educativa e numa sólida aprendizagem.

Ter em vista a percepção e o juízo de nossos alunos nos permitira entrar melhor no mundo deles. A opinião deles não é nossa norma; contudo, devolver para eles de maneira um pouco organizada a visão que tem do bom professor ou do professor desejado pode ser uma boa oportunidade para a reflexão deles e a nossa. Podemos encontrar aqui uma ocasião de comunicação significativa como nossos alunos, ao nos dizer como deveríamos ser, nos comunicar suas próprias necessidades tal como eles as vivem (MORALES, 1998, p. 35).

O professor deve procurar escutar mais o conceito que os alunos já têm ou formularam através do contato, do que seja um perfil de bom professor, ou até mesmo do professor que desejam e, através desse diagnóstico, refletir sobre suas próprias ações e o que pensam os alunos. Repensar sobre a prática pedagógica e as atitudes, em sala de aula, é imprescindível para que, se necessário, sejam elaboradas outras formas de ações compatíveis com as ideias dos alunos, que assumem papel importante como termômetro de suas atitudes em sala de aula. Contudo, as opiniões dos alunos - assim como as do professor - não traduzem a verdade absoluta. Enxergamos, nesse contexto, oportunidade de debate e reflexão sobre o assunto, em que ambos têm direito de voz. O professor deve oportunizar momentos de discussão com os seus alunos, pois pode ser que estes - através das cobranças que fazem ao professor - estejam demonstrando suas próprias dificuldades. 
O professor habilidoso trabalhará possibilitando oportunidades e subsídios para que eles próprios consigam conscientemente interpretar e suprir suas necessidades.

A personalidade de cada indivíduo atrai semelhantes, assim, na convivência escolar, o professor deve estar atento às suas ações perante a turma que o observa. Potencializar o que há de positivo em si mesmo é importante para esse profissional que lida diretamente com a formação de pessoas. Nada que é forçado, dura o suficiente até que os outros formem um conceito: o ideal é sempre ser verdadeiro consigo e com o próximo.

\begin{abstract}
Sem dúvida, há traços de personalidade mais promissores que outros para ser um bom professor e estabelecer um bom relacionamento com os alunos; entretanto talvez aqui, mais que insistir em traços, convenha insistir em atitudes. O que mais importa são nossas próprias atitudes e como concebemos nosso papel de professor (MORALES, 1998, p. 37).
\end{abstract}

É certo que alguns traços de personalidade são mais favoráveis à visão que os alunos têm do bom professor, embora nem sempre o que eles querem e esperam do professor seja o melhor para sua formação. Muito além de simples traços de personalidade estão às ações diretas que o professor produz constantemente em seus alunos e a visão de seu próprio papel como profissional da educação. Temos absoluto direito de sermos diferentes, mas é primordial o controle do que fazemos na relação com os alunos - que costumam reproduzir opiniões - e das ações que realizamos durante ou posteriormente à prática pedagógica. Ao professor, é necessário cautela ao falar e agir, haja vista que ele é um mediador de conhecimentos e formador de opiniões.

Para que o professor atinja esses pressupostos, é importante que ele se paute na afetividade, que é imprescindível à vida de todo ser humano, pois estamos em contato direto com outras pessoas e necessitamos dessa relação para sobreviver, desde que sejam sentimentos verdadeiros de ambas as partes envolvidas em um convívio saudável. “[...] não mostraremos uma proximidade afetiva que não está em nós, mas podemos tratar a todos com respeito o tempo todo" (MORALES, 1998, p. 37).

Não podemos demonstrar algo que não temos, por mais que nos esforcemos para fazer o contrário, em algum momento nos contrariamos e acabamos nos mostrando como realmente somos. A afetividade é algo que se tem ou constrói pelo outro sem esperar nada em troca; se não der para ser dessa forma, tratar o outro com respeito seria o ideal. Em se tratando da educação, a situação não é diferente, já que o professor não deve forçar a demonstração de sentimentos que não têm; mas, obrigatoriamente, 
respeitar a todos à sua volta pelo próprio papel de responsabilidade que assumiu perante a sociedade.

As cobranças se fazem reais e constantes, tanto na vida profissional quanto pessoal do professor, que deve ter no mínimo uma conduta ética e moral, pois esta mostra, verdadeiramente, quem pessoa é, e os valores morais que regem suas falas e ações.

Como já enfatizamos, o professor influencia a vida de seus alunos e cabe a ele a conscientização e reflexão sobre esse fator. Assumir essa realidade é importante, de modo que temos em nossas mãos a oportunidade única de fazer a diferença e procurar ensinar à nossos alunos valores essenciais ao desenvolvimento, produzindo subsídios para que saibam realizar suas escolhas com maior segurança.

Influência não se dá apenas na linha dos conhecimentos e do desenvolvimento intelectual; incide também no desenvolvimento emocional e social dos alunos. Podemos influir também no desenvolvimento moral, no discernimento dos próprios valores e no discernimento para saber o que eles querem fazer com suas vidas. Nós, professores, não somos tudo, é claro, mas temos uma grande influência, ou podemos tê-la, na vida de nossos alunos (MORALES, 1998, p. 39-40).

O professor deve estar apto a detectar falhas e dificuldades pessoais que possam prejudicar diretamente seu papel de formador. A realidade é que produz um enorme impacto na vida dos alunos, que observam e reproduzem o que viram; cada um a seu modo interpreta as ações e falas do professor. Portanto, podemos afirmar que as mudanças e aprendizagens podem ser boas ou ruins, dependendo apenas da disponibilidade do professor em ficar atento à tudo que realiza perante seus alunos, para que consiga trazer benefícios ao desenvolvimento pleno deles.

Não estamos defendendo que o professor esteja acima de tudo, que seja o único detentor do conhecimento e vá conseguir resolver todos os problemas, mas que ele é uma parte essencial no processo educacional e que deve refletir constantemente sobre seu papel e responsabilidade com suas falas e atos, que afetarão seus alunos diretamente, transformando-os ou não em cidadãos críticos e ativos socialmente. Para Mahoney (2005, p. 2.) “A escola é um meio fundamental para o desenvolvimento do professor e do aluno, ao dar oportunidades de participação em diferentes grupos; nesse meio, professor e aluno são afetados um pelo outro, e, ambos, pelo contexto onde estão inseridos". 
Tognetta e Vinha (2009) nos lembram que nem sempre os alunos podem expressar o que sentem; os problemas que enfrentam e suas expectativas são censuradas, contidas e até mesmo punidas. Em contramão à esta realidade que as autoras nos trazem como reflexão, o professor deve estar ciente de que é fundamental oportunizar aos alunos um ambiente propício de convivências múltiplas, de modo que um indivíduo aprenda com o outro e consigo mesmo a partir das vivências e descobertas de mundo. Portanto, o professor tem grande influência na vida de seus alunos, ao passo que trocam experiências e as avaliam como boas ou não para si.

O modo como os professores enxergam a criança é essencial para o sucesso da aprendizagem. Quando não julgam e procuram se aproximar do aluno, acreditam nele, observam seu comportamento e incentivam suas capacidades, ele tem tudo para crescer (CAVALCANTE, 2005. p. 54).

A criança é, essencialmente, um ser em constante busca da aprendizagem, pois ela está construindo sua personalidade e valores a partir de suas observações e relações com outras pessoas. Levando-se em consideração que permanecem grande parte de sua vida na escola, refletimos que o professor tem forte responsabilidade em tudo que ensina à essa criança. Assim, o professor deve conscientizar-se de que seu modo de tratar os alunos vai ter um peso imenso no que diz respeito a como e em que os alunos se tornarão na vida adulta.

O cuidado com o aluno vai muito além de dar um beijinho, elogiar e acarinhar. Muitas vezes o afeto é demonstrado de forma contrária: quando o professor é severo. Se ele é justo e chama a atenção de forma respeitosa, o aluno passa a admirá-lo e busca não decepcioná-lo (CAVALCANTE, 2005, p. 56).

Quanto ao professor ser "meloso", não quer dizer que ele está essencialmente sendo afetivo com seus alunos, pois essa não é a forma mais adequada de demonstrar seus sentimentos e respeito. É importante que o professor saiba lidar com a sua sala de aula, respeitando as diferenças, onde cada aluno tem suas particularidades e merece ser tratado com respeito e atenção. Assim, os próprios alunos começarão a tratar seu professor com o mesmo respeito, tornando harmoniosa a relação entre ambos e todos terão benefícios e alcançarão os objetivos propostos pela educação, que são a aprendizagem e a transformação individual e coletiva. Após a conscientização da 
relação professor e aluno, é essencial que haja uma reflexão sobre a relação entre a afetividade e o processo de ensino e aprendizagem.

\title{
A afetividade e o processo de ensino-aprendizagem
}

A relação entre professor e aluno é essencial para que exista o processo de ensino-aprendizagem, pois é através dessa relação que professor e aluno interagem e definem seu papel nesse processo, trocando experiências, dificuldades e conquistas. Segundo Mahoney (2005, p. 1) “O processo de ensino-aprendizagem só pode ser analisado como uma unidade, pois ensino e aprendizagem são faces de uma mesma moeda; nessa unidade, a relação interpessoal professor- aluno é um fator determinante".

Não se pode tratar de ensino e aprendizagem como dois pontos separados, pois ambos se completam e devem caminhar juntos, visando a uma melhoria da educação e, consequentemente, da vida dos alunos. Todavia, cabe aos professores observar que somente a partir das relações construídas em sala de aula com seus alunos e levadas também para fora do ambiente escolar é que ambos poderão obter resultados positivos na vida pessoal, profissional e acadêmica.

\begin{abstract}
A não satisfação das necessidades afetivas, cognitivas e motoras prejudica a ambos, e isso afeta diretamente o processo ensinoaprendizagem: - no aluno, pode gerar dificuldades de aprendizagem; no professor, gera insatisfação, descompromisso, apatia, podendo chegar ao estresse (MAHONEY, 2005. p. 2).
\end{abstract}

Constata-se que as relações construídas pelos professores e alunos são um forte fator de evolução ou desconstrução dos indivíduos, pois a insatisfação, em algum ponto específico da vida de ambos, pode gerar alguns problemas para ambas as partes e cada uma reagirá de modo bem particular, mas que serão, certamente, prejudiciais tanto na prática pedagógica quanto na aprendizagem dos alunos. "A valorização do componente afetivo no trabalho docente favorece aprendizagens significativas" (SANTOS, 2002. p. $110)$.

A afetividade torna-se, sem dúvida, um dos fatores relevantes na prática pedagógica do professor, pois facilita e contribui para a aprendizagem dos alunos e deixa o professor mais seguro diante de sua turma, que o respeitará e devolverá em troca absolutamente tudo que receber de seu professor: seja algo bom, seja algo ruim, pois os alunos costumam ter seu professor como exemplo a ser seguido. Assim, se essa relação 
for baseada na afetividade, obviamente, tanto o professor como os alunos terão mais facilidade de construir valores essenciais para uma boa convivência em sociedade e de entendimento das diferenças comuns a todo ser humano. "A construção de valores e atitudes cabe à escola, sim. O seu papel, professor, é identificar entre tantas opções o que pretende construir com sua turma. Valorizar o melhor de cada um é essencial para o crescimento" (CAVALCANTE 2005, p. 55).

É importante que o professor esteja sempre com a atenção voltada para cada aluno em particular, levando em consideração o que cada um tem de melhor e auxiliando a lidar com seus problemas, pois o aluno, quando se sente amparado em suas dificuldades, consegue lidar melhor com elas. A escola tem grande responsabilidade na construção de valores dos indivíduos que à ela foram confiados; portanto, ela deve estar ciente de que está formando e preparando indivíduos para conviver em sociedade. Sendo assim, a forma como esses valores estão sendo trabalhados na escola, no processo de ensino-aprendizagem, é um questionamento a se responder constantemente como meio de avaliar e realizar mudanças quando necessários. Segundo os PCNSParâmetros Curriculares Nacionais

Ao lado do trabalho de ensino, o convívio dentro da escola deve ser organizado de maneira que os conceitos de justiça, respeito e solidariedade sejam vivificados e compreendidos pelos alunos como aliados à perspectiva de uma "vida boa". Dessa forma, não somente os alunos perceberão que esses valores e as regras decorrentes são coerentes com seus projetos de felicidade como serão integrados às suas personalidades: se respeitarão pelo fato de respeitá-los. (BRASIL, PCN, 1997. p. 80)

O convívio dentro do ambiente escolar deve ser bem pensado e organizado para que haja harmonia e respeito entre todos; do contrário, ele acarretará vários problemas difíceis de serem solucionados. Fazer uma ligação entre justiça, respeito e solidariedade com os alunos, referindo-se sempre à uma vida digna e saudável que esses pontos trarão, se vivenciados em sua plenitude, é primordial, pois só assim entenderão que viver bem consigo e com os outros requer compromisso e responsabilidade. Portanto, toda prática pedagógica deve ser iniciada a partir de uma boa relação entre professor e alunos, tornando recompensador o processo de ensino-aprendizagem. E uma forma de construir boas ações pedagógicas na escola em busca das relações afetivas é considerar a teoria de um dos teóricos que comprovadamente mostrou que a afetividade é o caminho para uma educação eficaz. Trata-se da teoria de Henri Wallon (1879-1962), 
para quem o desenvolvimento cognitivo da criança, a partir da psicogênese, deve ser considerar o ser no seu todo de forma contextualizada. A seguir, apontamos alguns estudos relacionados à teoria psicogenética desse estudioso, que revolucionou a educação do século XX.

O ser humano é essencialmente afetivo, em graus diferenciados, mas necessita desse sentimento para conviver em sociedade em momentos bem diferenciados, pois " $\mathrm{O}$ potencial afetivo do ser humano é o que o capacita para conhecer as circunstâncias e os fatos do e no mundo" (MOSQUERA, 2006, p. 130).

Nota-se que é o potencial afetivo que traduz a capacidade dos indivíduos de interagir com as outras pessoas à sua volta, levando-o a conhecer os fatos que acontecem diariamente ao seu redor:

\begin{abstract}
A pessoa vive e age numa realidade circundante, o seu meio social e a natureza, onde conhece o mundo que a rodeia, em especial as pessoas e estabelece suas relações sociais. No processo de sua atividade e relação com os outros, desenvolve e experimenta sua afetividade. Em outras palavras, age com os sentimentos e suas cognições ou cognições e sentimentos. (MOSQUERA, 2006. p. 128)
\end{abstract}

Todos os indivíduos vivem de acordo com a realidade à sua volta, o que define seu estado emocional diante das diversas situações do cotidiano, concorrendo para a estabilidade ou desestabilidade das relações interpessoais, mas experimentando a diversidade dos sentimentos humanos. São perceptíveis as dificuldades existentes no que diz respeito à convivência entre os indivíduos e, quando trazemos essa questão para a infância, a situação complica-se ainda mais, pois é visível a perda dos valores que norteavam e embasavam melhor essa relação entre as pessoas antigamente:
A afetividade, expressada pelos sentimentos, reflete as relações das pessoas, e é essencial para a atividade vital no mundo circundante. Pelas modificações dos sentimentos e sua expressão comportamental, podemos analisar a mudança de atitude do ser humano frente às circunstâncias mutáveis ou estáticas de sua vida, em determinados contextos de tempo e espaço. (MOSQUERA, 2006. p. 130)

Estamos expressando, a todo instante, nossos sentimentos, angústias ou alegrias, consciente ou inconscientemente, já que nas nossas expressões faciais, corporais ou até mesmo nas nossas falas, conseguimos detectar, através da atenção, o estado emocional ou opiniões das pessoas, fatores determinantes na convivência entre indivíduos 
inseridos em uma sociedade, principalmente quando o respeito é o princípio norteador dessas relações.

Considera-se, a partir dos estudos teóricos, que os sentimentos são indispensáveis e indissociáveis ao ser humano, pois um não existe sem o outro; portanto, o autoconhecimento faz-se necessário a qualquer pessoa que tem por finalidade viver bem socialmente e, a partir daí, tentar lidar melhor com os sentimentos das outras pessoas. Assim, vivenciar a afetividade no ambiente educacional, é fundamental para que as crianças possam interpretar o mundo de uma forma mais sensível, atribuindo valores a si mesmas e ao próximo, no intuito de contribuir para um mundo mais humano, menos capitalista e competitivo.

\section{Considerações finais}

Após a realização dos estudos teórico-metodológicos, a partir da pesquisa bibliográfica, pode-se concluir que as relações interpessoais e afetivas no contexto escolar exercem forte influência nos processos de ensino e aprendizagem.

Conforme discutido nos aportes teóricos deste trabalho de conclusão escrito como exigência para conclusão da especialização em Psicopedagogia Clínica e Institucional na UNICAP-Universidade Católica de Pernambuco em Parceria com o CEPAI- Centro Psicopedagógico de Atividades Integradas, salienta-se a necessidade da quebra de paradigmas que ainda distanciam as relações afetivas entre professor e aluno e família e aluno e que afetam diretamente o processo de aprendizagem dos alunos. Portanto, cabe à todos, que acreditam numa educação eficaz e significativa, um empenho contínuo em busca da propagação da afetividade no contexto escolar.

Conclui-se, portanto, que a afetividade está diretamente ligada aos processos de ensino e aprendizagem, pois quando há um contexto escolar baseado na afetividade e respeito às diferenças e individualidade de cada um, esta aprendizagem se dá de uma forma mais rápida, simples e concreta.

Finalizando as reflexões sobre a afetividade e os processos de ensino e aprendizagem, espera-se que outros pesquisadores possam vir a desenvolver mais estudos sobre esse tema, que é fundamental nos dias atuais, principalmente na educação vivenciada na escola, para que haja uma expansão consciente sobre a importância da afetividade na relação professor e aluno em busca da formação de sujeitos participativos e atuantes na sociedade, que almeja um mundo de paz e de valorização humana. 


\section{REFERÊNCIAS}

BRASIL, Secretaria de Ensino Fundamental. Parâmetros Curriculares Nacionais: apresentação dos temas transversais, ética/ Secretaria de Educação. Brasília: MEC/SEF, 1997.

CAVAlCANTE, M. Como criar uma escola acolhedora. Nova Escola, São Paulo: Abril, n. 180, p. 51-57, março 2005.

MAHOnEY, A. A.; AlMEIDA, L. R. de. Afetividade e Processo de EnsinoAprendizagem: contribuições de Henri Wallon. São Paulo, 2005.

ZABALZA, M. A. Qualidade em educação infantil. Porto Alegre: Artmed, 1998.

OLIVEIRA, M. M. de. Como fazer projetos, relatórios, monografias, dissertações e teses. Rio de Janeiro: Elsevier, 2005.

PRESTES, M. L. de M. A pesquisa e a construção do conhecimento científico do planejamento aos textos, da escola à academia. 3 ed. São Paulo: Rêspel, 2008.

SANTOS, G. V. dos. Influência da afetividade no processo ensino- aprendizagem. 2002. Monografia (II Curso de Especialização em Educação Infantil). Setor de Ensino à Distância/ Centro de Educação/ Universidade Federal da Paraíba. João Pessoa-PB.

TOGNETTA, L. R. P.; VINHA, T. P. Valores em crise: o que nos causa indignação? In: LA TAILlE, Yves de; MENIN, Maria Suzana de Stefano. Crises de Valores ou Valores em Crise? Porto Alegre: Artmed, p. 15-45, 2009.

GIL, A. C. Como elaborar projetos de pesquisa. 4 ed. São Paulo: Atlas, 2006.

\section{Como referenciar este artigo}

MEDEIROS, Maria Fabrícia de. O papel da afetividade na relação professor e aluno e sua implicações na aprendizagem. Revista on line de Política e Gestão Educacional, Araraquara, v. 21, n. esp.2, p. 1165-1178, nov. 2017. Disponível em: <http://dx.doi.org/10.22633/rpge.v21.n.esp2.2017.10179>. E-ISSN:1519-9029.

Submetido em: 30/07/2017

Aprovado em: 18/09/2017 